\title{
The primary school as a therapeutic community
}

\author{
Gary Winship and Shelley MacDonald
}

Gary Winship and Shelley MacDonald, both are based at the University of Nottingham, Nottingham, UK.
Received 6 January 2016 Revised 6 January 2016 Accepted 8 January 2016

\begin{abstract}
Purpose - The purpose of this paper is to consider the changes underway in the delivery of services to children and young people in schools, not least that OFTSED will soon be routinely carrying out an assessment of mental health provision in schools. This paper considers the policy context to these changes and the recent initiatives that are informing the evolution of initial teacher training. Alongside the changes in Child and Adolescent Mental Health Services there are an increasing number of schools developing counselling and psychotherapy services. How can the School counsellor look to develop a who school as therapeutic community.

Design/methodology/approach - A case narrative is presented of a seven-year-old child who was referred to the school counselling service. The narrative draws attention to the array of dynamic interactions, from peers to teachers to parents which the school counselling manager encountered.

Findings - It is argued that it is necessary for the school counsellor to have a framework for understanding how all parts of the school work together and it is proposed that we might usefully consider the primary school as a therapeutic community.

Originality/value - There are a raft of policy changes and practices in recent years that have altered the landscape of early intervention and the mental health agenda in primary schools. This paper captures this debates and consider how therapeutic community ideology is positioned as an opportunity to think more expansively about mental health in primary schools.
\end{abstract}

Keywords Therapeutic communities, Teachers, Psychotherapy, Early intervention, Primary schools, School counselling

Paper type Conceptual paper

\section{Policy context}

The Department for Education's (2014) guidelines: Mental Health and Behaviour in Schools (first published June 2014, updated March 2015) positions schools as pivotal in delivering primary mental health care for children and young people. The Department for Education's (DfE's) use of the term "Mental Health" might have run the risk of stigmatising some young people who come into the orbit of formal therapies in the setting of school, but overall the document testifies to the way in which the debate about mental health has percolated across professional disciplines, informing teachers and mental health practitioners alike, and as far as schools are concerned, mental health is now everyone's business.

Mental Health and Behaviour in Schools (2014/2015) emphasises "key" presenting areas such as substance misuse, self-harm, eating disorders and attachment disorders and recommends evidenced-based approaches, particularly cognitive behavioural and psychoanalytic therapies, coming in the tow of emerging research that school-based counselling and psychotherapy is effective (Danuinaite et al. , 2015). The DfE's guidance coincides with the comprehensive review of initial teacher training (ITT) which was carried out by Sir Andrew Carter and published in 
January 2015 which made key recommendations that all ITT should include a purposeful grounding in the theory of child and adolescent emotional development with an emphasis on attachment theory. The Carter Review also concluded that there should be accredited training in attachment-based practice for all staff working in schools. The Government's response to the Carter Review has seen the Secretary of State for Education establish a sector task force to identify a framework of Core ITT content.

There has been considerable upheaval in Child and Adolescent Mental Health services (CAMHS) where resources have been stretched thin with CAMHS undergoing a strategic relocation from the $\mathrm{NHS}$ to local authority led provision with the DfE superseding the NHS as the main policy driver for children's mental health services. The cross-party House of Commons Health Committee Report 2014-2015 (HC, 342) Children's and Adolescents' Mental Health and CAMHS recognised the crisis of service provision and concluded that schools needed to do more to fill in the gaps left by the shortfall of CAMHS resources, recommending that the DfE do the following:

\footnotetext{
Look to include a mandatory module on mental health in initial teacher training, and include mental health modules as part of ongoing professional development in schools for both teaching and support staff. We also recommend that the DfE conducts an audit of mental health provision and support within schools, looking at how well the guidance issued to schools has been implemented, what further support may be needed, and highlighting examples of best practice. OFSTED should also make routine assessments of mental health provision in schools. It is clear that education about mental health could and should contribute to prevention and support for young people. We recommend that the DfE consult with young people, including those with experience of mental health issues, to ensure mental health within the curriculum is developed in a way that best meets their needs ( $\mathrm{HC} 342$ House of Commons Health Committee, 2014, pp. 6-7).
}

These developments, especially the plan to make routine assessments of mental health provision as a function of OFSTED inspections, will significantly shape the work of schools in the coming years, and will have especial implications for the counsellor and psychotherapist working in the school. It is into this mix of evolving ideologies and service developments in schools that we might consider how therapeutic community ideas can come into play. While concentrating on the focal time spent with the young clients, either individually or in a group situation, it is arguable that school counsellors and psychotherapists should pay heed to the overall context of the school as a psychologically informed therapeutic environment. In a broad sense we need to position the concept of the school, any school, as an adapted therapeutic community with the school counsellor or psychotherapist as a facilitator who fosters a milieu that we might consider in terms of a whole school approach to sustaining a therapeutic milieu.

\section{Forty thousand hours of primary mental health care}

Schools are where most children from five onwards spend a large part of their waking week. It is got good capture. If you want to identify and support vulnerable children then school is about as reliable an access point as you are going to get, and recent government policy is now alert to this. Psychotherapists working in a school are much less likely to write a "did-not-attend" on their paperwork than their colleagues sitting in a clinic or agency waiting for their client to make the journey to meet them. If a child does not turn up to school, due to something other than ill health, there is a system that mobilises around them that tries to support their attendance.

In the late 1970s Rutter et al. (1979/1994) tallied up that on average children will spend 15,000 hours Q2 in secondary school education. Rutter argued that if you have a well-oiled system, then there is a great deal of scope and time to impact positively on the lives of children. If you were to add the amount of time that children will spend in pre-school educare, and then on top of that add the time spent in primary school and finally in secondary school education, the tally starts to top up to nearly 40,000 hours. And this does not take into consideration the increase in wrap around care as children's school days are elongated with the provision of breakfast clubs and after school clubs.

At its best the school system is emotionally resourced by teachers who create a facilitating environment from the classroom to the playground where the therapeutic potential of the school amounts to more than 30 hours a week of contact time. Teachers are crucially positioned to support emotional well-being in children. Music (2007) draws attention to a case where several 
children were referred for counselling from one class, while another class, ostensibly with a parallel population of pupils, had no referrals. Although Music concluded that the discrepancy was due to a differential in teacher experience and capacity to contain disruption in the classroom, there might be more complex dynamics at play when considering the ebb and flow of traffic between different classes and the therapy room. Some teachers are more attuned to the emotional lives of the children and this can afford a greater emotional literacy within the children themselves, but it is necessary to look beyond the disrupted classroom. It could be seen as a key role of the school psychotherapist to try to support emotional attunement across all staff from playground supervisor through to the Head Teacher. It is the school as a whole is seen as the challenge of fostering an encompassing therapeutic environment.

We are set to see an increase in the number of counsellor and psychotherapists working in schools. In some countries, China and Wales for instance, it is a requirement that all secondary schools provide counselling services and employ a dedicated counsellor. In England all boarding schools require counsellors. Interventions span individual and group therapeutic discourses and the theoretical denomination of school counsellors usually coalesces under the rubric of humanistic, solution focused and interpersonal approaches (Lines, 2002). Although group approaches, such as belonging groups or peer support counselling groups, are implemented in some areas (Boulton, 2005), these are less common place than individual approaches. However, there appears to be an increase in the flexibility of approach among psychotherapy and counselling practitioners responsive to different local needs reflecting a new ethos of practice that begins with a systemic view of the child's presentation, where old orthodoxies of practice welded to one particular school of thought, for example, a purist psychoanalytic or purist cognitive approach are modified from an array of best-fit approaches (Bor et al., 2002). At best this modern model of school counselling and psychotherapy seems to be a more socially contextualised engendering a sort of "ecological" view of clinical presentation that is both child focused but collaboratively constructed with regard to working openly with an array of stakeholder professionals where confidentiality is not compromised, but rather fitted to the policy agenda for joined-up approaches to care (Department of Health, 2004). At best the school psychotherapist is no longer viewed as isolated, distant and aloof, but rather an integral component of the team and the life of the school. Music (2007) refers to the case of a seven-year-old who was trashing classrooms, hitting teachers and fellow pupils. The child became a receptacle for a number of negative projections from the teachers, meanwhile the therapist saw a very worried little girl who was enduring a dire family situation. Communication between therapist and teacher was essential to inform a whole picture of the child's troubled life.

It is progressive to envisage a social system which recognises the importance of early intervention where mental health issues are seen to be part and parcel of the community of all primary and secondary school life, the school as life in a small dose. That is to say, young people learn that if they are feeling more than ordinarily sad, angry or anxious, you can see a therapist who will help you. But we might consider an even more encompassing agenda where the whole school approach, with an emphasis on healthy peer relationships, social inclusion including enfranchisement, is seen part of an aspirational therapeutic community that holds children and young people across their whole school life.

\section{School as TC - school as community hub, keeping the family in mind}

Schools are the holders of dreams, realities, responsibilities and they offer a hefty resuscitation kit. For some children school is the only place they feel truly safe. According to the Office for National Statistics as soon as children come into the orbit of a school in the UK they are less likely to die at the hands of another. But sadly, some children and young people do take their own lives. For under 14-year-olds point there is a relatively small, though significant number of suicides every year, and there are probably more hidden suicides because the recording of a suicide verdict for children under ten is very rare as intention is debatable. Instead, verdicts of "accident" are returned. Although we need much more research in this area, anecdotally at least, we know that many school-age suicides take place in the holidays when the schools are closed and children are at home, possibly isolated from friends and beyond the containing gaze of teachers and other school staff.

\begin{tabular}{l|l|l} 
VOL. 37 NO. 12016 & THERAPEUTIC COMMUNITIES: THE INTERNATIONAL JOURNAL OF THERAPEUTIC COMMUNITIES & PAGE 3
\end{tabular} 
For many years now, schools have been expanding their provision in the form of breakfast clubs and after school activities, offering coverage from 8 a.m. to 6 p.m. Schools have not yet been asked to do after hours outreach, but that may be on the horizon. For some families who do not have paid work, the school community is one of the few public buildings they enter and many parents will look to the school to seek guidance on how to navigate stressful life events. Often parents look particularly to the Head Teacher of the school as the beacon of hope when times are difficult. For many families, schools broker the space between familial collapse (from divorce, bereavement and trauma) to statutory intervention. When things get difficult for families, when a range of multi-agencies become involved, schools are at best helpfully experienced as on-side, advocates based on pre-existing relationships, seen by parents to be operating in the best interests of their children. Primary schools are particularly good places to target early intervention. The percussive beat of poverty and deprivation might cast an early gloomy shadow, marching children in that direction unless the school can find another rhythm. By the turn of the millennium, UK adolescent mental health appeared to have deteriorated more significantly than other European countries (Collishaw et al., 2004). We live in an age of divorce where children and young people are brought up in increasingly complex constellations, with Q3 blended or reconstituted families and absent fathers (Murphy and Fonagy, 2012). Gulliver et al. (2010) have drawn attention to the reasons why young people, and perhaps their parents, appear to be reluctant to access services, citing stigma, embarrassment, poor mental health literacy as the most significant barriers to help-seeking behaviour. However, Gulliver et al. (2010) also noted that there was evidence that the young people who had perceived positive past experiences of mental health support were the ones more likely to seek help when troubled. So providing a positive experience of counselling in primary schools might well be a crucial attribute of a system of early intervention that increases the likelihood of young person seeking help later in the future.

The extraneous circumstances of targeted interventions with an "identified child" who is in distress for whatever reason, needs to be considered against the backcloth of the effect of parental involvement, sibling and peer relations as well as the effect of teacher and significant other involvement, for example grandparents and extended family members. Even where family therapy is not ostensibly the locus of a programme of intervention, the primary school psychotherapist needs to always keep the family in mind. In the School therapy room it is not so much the case that the family is "always under the couch" as Freud would say, but rather it is the case that the family are always in the sand-tray.

Some school psychotherapists work directly with the family. Schools can be provocative places for parents, activating their own experience of school when as a child. Sometimes drop off and pick up times can be fraught. Inter-parental conflict can overspill into both playground and classroom and this needs to be managed by staff and children alike and the psychotherapist can be mindful of these interactions. We might conceive of the school counsellor and psychotherapist delivering interventions according to three broad systems within the overall school therapeutic community; children and their peers; families; teachers and other professional stakeholders. Mapping formal interventions in these terms is an oversimplification, but the model offers a baseline for examining how these system dynamics interact. The school therapist needs to develop a mental working model of a whole school so that the discrete interventions of counselling and psychotherapy can be held in the context of knowledge of roles and specialisms of other stakeholders. The establishment of a classroom milieu that contains and even heals emotional distress among pupils contributes to educational attainment (Rutter et al., 1979/1994; Q4 Hall et al., 2002; Durlak et al., 2011). Rutter et al.'s (1979/1994) extensive study of pupil achievement and well-being demonstrated that "whole school processes" were inextricably linked to favourable outcomes. Mental health matters are subject to contagion effect, so the school psychotherapist should be alert to patterns, for example a spate of self-harm or increased risk taking activity in the school playground. Working with teachers in order to raise consciousness about emotional needs can subtly re-orientate teacher perceptions of children who might otherwise have perceived a child to be badly behaved. The school psychotherapist can contribute to an understanding of the nature of a "troubled" child. Based on longitudinal research, a range of presenting mental health problems, for instance early onset personality disorder and self-harm, have a tendency to dissipate across time given the conducive conditions for social development and adjustment, with schools playing a central role (Johnson et al., 2000),

\begin{tabular}{l|l|l} 
PAGE 4 & THERAPEUTIC COMMUNITIES: THE INTERNATIONAL JOURNAL OF THERAPEUTIC COMMUNITIES & VOL. 37 NO. 12016
\end{tabular} 
so the school therapist should be alert to the everyday prevailing therapeutic climate of the school where some children will be helped without formal psychotherapy intervention.

Psychotherapists working in schools will know well that sometimes teacher colleagues can have unrealistic expectations of the outcome of specialist counselling interventions with children. It can be the case that the teacher hopes that a referral to the school psychotherapist will bring about a swift solution of a presenting problem. Though this might be the case in some instances, often the aim for the psychotherapist will be situate the psychotherapy sessions as an adjunct to the overall support that the teacher brings to their work with the child. One example of a favourable outcome to a process of teacher group consultation was in Brent in a project described by the DfE and Schools and the Department of Health as; "a model of good practice" (Music, 2007). Staff from the Tavistock Clinic in London acted as external consultants with the aim of increasing teacher understanding about the underlying meaning of pupil disruptive behaviour and improving the capacity of teachers in identifying children at risk and in need of specialised psychotherapy intervention. After three years, 97 per cent of the teachers $(n=120)$ felt more able to persevere with challenging pupils and 83 per cent reported feeling less stressed after talking about their work in fortnightly staff groups. It was surmised that the significantly lower rate of absence among staff team was also a consequence of the alleviation of stress in the staff group.

By working closely through all levels of the school hierarchy from Head Teacher to classroom assistant, the psychotherapist can support a whole school approach mental well-being (Jackson, 2002). Working directly with teachers, often in informal discussions, the psychotherapist can contribute to building on the ordinary pastoral skills of any good teacher (Salzberger-Wittenberg et al., 1993; Hall et al., 2002). The same principles can be applied to interactions with parents. In this sense, the psychotherapist is facilitating therapeutic encounters and a culture of inquiry about well-being throughout the school; in the staff room, the corridors, the classroom and the playground. The following case vignette illustrates some of the system interactions that can contribute to the development of adapted therapeutic community milieu in a primary school.

\section{A case narrative: young citizen Kane}

Eight year-old Kane was referred for therapy in spring term. There were concerns about increasing unruly behaviour that could not be easily managed by the teachers. Kane was a likeable boy, not unpopular, and there seemed to be a mismatch between the Kane who was amiable and this new Kane who was increasingly unsettled. He began individual sessions with a trainee counsellor on placement, and there was some good progress made in terms of helping Kane talk about what he was finding difficult. But there seemed to be something stuck in terms of the split between "good Kane" and "angry Kane". Sometimes the school therapy manager had the feeling that Kane only wanted her and his therapist to see the good Kane. During one week, she saw Kane sitting outside of the Head Teacher's office on several occasions and when Kane came to his next session she asked him how his week had been. Kane responded, "really good". Now the therapy manager had a choice; should she tell Kane that she had seen him outside of the Head's office or not? In the end she decided to open up the debate responding; "Oh, has it been really good because l've seen you sitting outside the Head Teacher's office this week so I thought something might have been troubling you?" Kane nodded and a dialogue began.

A few months later Kane's individual sessions were progressing well. One week he turned up at the lunchtime drop-in service with his friend, Amy, in tow. In a conversation with the therapy manager about counselling, Amy appeared to struggle to gather her thoughts. Kane intervened with; "Amy don't look like her dad, they're not the same colour and everyone's saying he's not her dad". Amy was taken back by Kane's openness with the therapist but she quickly accepted the rules of engagement and began a hesitant account of her upset.

A few days later Amy's mother complained to Kane's teacher that Kane had been saying unkind things about Amy's parents. The teacher referred her to the therapist to discuss the matter further. In the meeting with the mother, the therapist said she felt that Kane was trying to be helpful in the drop-in session, and that perhaps he had opened up a space where the whispers of others could be thought about openly. The mother then talked about the complexities of her family life, and she left the meeting reassured that her daughter's situation was being thought about.

\begin{tabular}{l|l|l} 
VOL. 37 NO. 12016 & THERAPEUTIC COMMUNITIES: THE INTERNATIONAL JOURNAL OF THERAPEUTIC COMMUNITIES & PAGE 5
\end{tabular} 
Elsewhere, it was apparent that Kane was beginning to talk the language of therapy; he seemed to grasp an understanding of emotions and feelings, was at ease with this. A teacher told the therapy manager that Kane had been overheard in the playground talking about how good it was to have a person; "to go talk to about things that bother you". Soon Kane could be relied upon to be making suggestions to his peers that they should go to the drop-in sessions, as he had done with Amy. He became something of an ambassador for the counselling service. When Kane's teacher struggled to contain him in the class she came to talk to the therapist and together they tried to understand how his early life might be impacting on his behaviours. The counselling manager proposed a formulation which was that the occasions when Kane ended up outside the (male) Head's Teacher's office might be considered in light of the recent loss of Kane's father from the family home. The teacher later reported that this understanding had been helpful and Kane's exclusions from class were reduced. Later, when Kane's mother came to the therapist as part of the parent partnership work, the therapy manager able to make links between Kane's behaviour and the pain of having an absent father. Further discussions between the therapist manager and the teacher yielded further insight about the number of children in the class whose fathers were absent. The teacher decided to allocate a special circle time slot to think generally about fathers, including the present of step father's, encouraging all of the children to be sensitive to the different circumstance of their classmates.

\section{Reflections - the ear to the emotional life of the school therapeutic community}

One of the challenges for the school psychotherapist is to hold in mind the proximity of various relationships around the school. In Kane's case the therapist was able to draw from an array of observations, from her interactions with him, his progress in the sessions, how he was in the playground and the corridors and so on. If the therapist had not brought her observation of Kane sitting outside the head master's office, Kane might have been left feeling that the therapist was colluding with his "best-self". And we can see the important role of peer relations and the ripple effect of encounters. Kane's curiosity agitated an important discussion with Amy that brought her mother to have important conversation with the teacher and therapist. Something was able to be held in mind and here we see elements of a therapeutic milieu rippling across a range of intersecting dynamic events. These elements of dialogue, peer relations and compassion as they evolve alongside the weave of authority and empowerment start to resemble the frame we can consider under the rubric of a therapeutic community, a culture of enquiry where participants can feel enfranchised.

On the one hand it is necessary for the school psychotherapist to be seen as part of the whole school approach, but realistically, there are periods where the role will feel isolated, where the school psychotherapist may feel marginal. Hinshelwood (1994) talks about the way in which psychotherapists operate as satellites in large organisations like the National Health Service, whereby the distance serves a function in creating the necessary conditions for being on the one hand close enough to know what is going on, but then again distant enough to offer a fresh pair of eyes. This idea of a satellite psychotherapist seems apposite when it comes to thinking about the role of the psychotherapist working in an organisation such as a school, a pupil referral unit or a care home. The role can be tricky insofar as the therapist might feel torn between being inside and outside the staff team. Colleagues might feel that the therapist is parachuting in and out for an hour a week with a client, and not having to suffer the long haul challenge of a particularly needy child. There may be some elements of envy or resentment from teacher colleagues, that the psychotherapist has less prolonged contact, with a small number of children.

For the school psychotherapist and counsellor, it is helpful to step inside the world of the teacher to take time out for whole class observations before starting with a child in one-to-one counselling. Who runs the school and how they run the school matters. Benign, collaborative, consultative leaders create that culture within the school. Autocratic leaders create a different dynamic within their schools. The governors also have a very defining role. Schools that are a matter of half a mile from one another can serve very different catchments with distinct characteristics. School psychotherapists should walk around the streets of the community they serve.

\begin{tabular}{l|l|l} 
PAGE 6 & THERAPEUTIC COMMUNITIES: THE INTERNATIONAL JOURNAL OF THERAPEUTIC COMMUNITIES & VOL. 37 NO. 12016
\end{tabular} 
Anxious, neurotic children are often micro-readers of mood in a teacher and peers. Children who experience domestic violence, for example, often have a 360 degree attunement to their environment born out of needing to be hyper alert in their homes, waiting for the voice to rise, the door to slam, the plate to smash. They might be better at hearing changes in intonation, for example, or momentary pauses in the teacher's response. Both might unsettle the child and trigger a behavioural issue which then disrupts the class. These sensitive children and the ones who are most likely to "know" something is amiss. A particularly needy child came straight up to the school counsellor one morning and asked, "What's wrong?" The counsellor asked; "What do you mean what's wrong?" The child said; "The staff are sad". She was right for staff, though not visibly upset, had been informed of a death of a colleague that morning and were deeply affected. They emanated a sadness that this child could read for she was particularly literate in reading emotional turbulence. The counsellor agreed there seemed to be a sadness that was around the school. This child was responding to a school community event that impacted on all the school and was, indeed, shared by the Head Teacher with the whole school later on that day.

Working, living, learning and thinking together breeds a unique sociability and counsellors have a history of working with a model of confidentiality that can be too isolating. The school-based psychotherapist should look at the school as a group organism and see individuals referred as part of a group phenomenon, and see themselves as part of that network of communications. The therapist can be attuned to the way in which emotional debris flies around a classroom where children who are experiencing demanding home lives can be vulnerable to projections. One suspects that there will be an upsurge in the frequency and range of public mental health issues that will confront all of us in the coming years. As financial resources are shorn in dark economic times, we are yet to see the full impact of the diminished coherence of public health prevention programmes.

So what is to be done to combat this decline into hard times? Into the fray we will see the school system as a political nodal point, a battleground of ideologies where education and welfare are locked in together as they were once before in bygone times. As much as the education system has been the bedrock for mass immunisation programmes that has seen the eradication of any number of terrible diseases, we should likewise consider schools as committed to a full immunisation programme aimed at making significant inroads into mental illness. Imagine what it would be like if schools could be as equipped to deliver mental health prevention programmes just as universally as immunisation. Health and education must be an allied comprehensive public service agenda. School leagues tables in the future may be less concerned with success in terms of exam results, and more concerned with gauging outbreaks of illness and evidence of social cohesion. Where the NHS falls short, as it seems inevitably set do so, the need for health inventiveness in schools will be vital. To some extent this may be a return to an age pre-NHS, even pre-welfare (from the late 1800s onwards) when education served a role in driving forward a national education agenda that was explicitly the corner stone of ensuring a basic level of wellbeing for all children. Indeed, perhaps the rise of the NHS took away some of the responsibility of the education system as focal point for ensuring children's welfare and well-being.

Education and health in a time of austerity will require our national education system to re-invent itself out of necessity. A rejuvenation of the idea of what was once called the progressive schools movement, with schools operating as therapeutic communities would seem to be indicated. It is timely then to re-visit the idea of a whole school approach and to develop the intrinsic role that the school psychotherapist can play in facilitating a therapeutic milieu where vulnerable young people can be engaged and held. The Every Child Matters (ECM) (Department of Treasury, 2003) agenda, spanning disciplines and professional interests, offered an ambitious vista for converging health, education and social service provision. The ECM guidance called for multi-agency collaboration and proposed that services should be developed in schools in order to meet the aims outlined in the Children's National Service Framework for developing "tier 2" primary care services in schools which would stand alongside services in GP surgeries and other community settings. It should be stated that teachers and pupils are already familiar with working alongside educational psychologists, connexion workers, CAMHS staff, educational welfare officers and school counsellors and so on. However, we now exist in post ECM times and the dissolution of the ethos of this agenda has yet to fully unfold.

\begin{tabular}{l|l|l} 
VOL. 37 NO. 12016 & THERAPEUTIC COMMUNITIES: THE INTERNATIONAL JOURNAL OF THERAPEUTIC COMMUNITIES & PAGE 7
\end{tabular} 
The idea of school as therapeutic community more universally needs to be refracted through the challenge of assembling coherency from the remaining partitioned ideologies of education and health. Not all teachers are committed to thinking about issues relating to mental distress (Weare, 2004; Winship, 2008). Indeed, Ecclestone and Hayes (2010) have described the emergence of the mental health agenda in schools as a Dangerous Rise in Therapeutic Education, though this position seems increasingly marginal. It is timely to consider developing and cohering a whole system approach whereby we can develop schools that can operate as adapted therapeutic communities ensuring the most conducive conditions which will benefit all the stakeholders.

\section{References}

Bor, R., Ebner-Landy, J., Gill, S. and Brace, C. (2002), Counselling in Schools, Sage, London.

Boulton, M. (2005), "School peer counselling for bullying services as a source of social support: a study with secondary school pupils", British Journal of Guidance and Counselling, Vol. 33 No. 4, pp. 485-94.

Collishaw, S., Maughan, B., Goodman, R. and Pickles, A. (2004), "Time trends in adolescent mental health", Q5 Journal of Child Psychology \& Psychiatry, Vol. 45, pp. 1350-62.

Danuinaite, D., Cooper, M. and Forster, T. (2015), "Counselling in UK primary schools: outcomes and predictors of change", Counselling \& Psychotherapy Research, Vol. 51 No. 4, pp. 251-61.

Department for Education (2014), "Mental Health and Behaviour in Schools”, DfE, Gov. UK.

Department of Health (2004), "Children's National Service Framework”, HMSO, London.

Department of Treasury (2003), "Every Child Matters", HMSO, London.

Durlak, J., Weissberg, R.P., Dymnicki, A.B., Taylor, R.D. and Schellinger, K.B. (2011), "The impact of enhancing students' social and emotional learning: a meta-analysis of school-based universal interventions", Child Development, Vol. 82 No. 1, pp. 405-32.

Ecclestone, K. and Hayes, D. (2010), The Dangerous Rise of Therapeutic Education, Routledge, London.

Hall, C., ECM, E. and Hornby, G. (2002), Counselling Pupils in Schools, Skills and Strategies for Teachers, Routledge, London.

HC 342 House of Commons Health Committee (2014), "Children's and Adolescents' Mental Health and CAMHS", Third Report of Session 2014-2015, Stationary Office, London.

Hinshelwood, R.D. (1994), "The relevance of psychotherapy", Psychoanalytic Psychotherapy, Vol. 8 No. 3 , pp. 283-94.

Jackson, E. (2002), "Mental health in schools. what about the staff?", Journal of Child Psychotherapy, Vol. 28, pp. 129-46.

Johnson, J.G., Cohen, P., Kasen, S., Skodol, A.E., Hamagami, F. and Brook, J.S. (2000), "Age-related change in personality disorder trait levels between early adolescence and adulthood: a community-based longitudinal investigation", Acta Psychiatrica Scandinavia, Vol. 102, pp. 265-75.

Lines, D. (2002), Brief Counselling in Schools - Working with 11-18 Year Olds, Sage, London.

Murphy, M. and Fonagy, P. (2012), "Mental health problems in children and young people", Chapter 10, Q7 The Annual Report of the Chief Medical Officer, UK Government.

Music, G. (2007), "Learning our lessons: some issues arising from delivering mental health services in schools", Psychoanalytic Psychotherapy, Vol. 21 No. 1, pp. 1-19.

Rutter, M., Maughan, B., Maughan, B., Mortimore, P., Ouston, J. and Smith, A. (1979/1994), 15,000 Hours Secondary Schooling and their Effects on Children, Paul Chapman Publishing, London.

Salzberger-Wittenberg, I., Williams, G. and Osborne, E. (1993), The Emotional Experience of Learning \& Teaching, Karnac, London.

Weare, K. (2004), Developing the Emotionally Literate School, Paul Chapman, London.

Winship, G. (2008), "Working with staff dynamics in an educational setting: the staff support group that wasn't Q8 to be", in Kennard, D. (Ed.), Staff Support Groups in the Public Sector, Wiley, London. 


\section{Further reading}

Gulliver, A., Griffiths, K.M. and Christensen, H. (2012), BMC Psychiatry, Vol. 10, p. 113.

\section{Corresponding author}

Gary Winship can be contacted at: Gary.winship@nottingham.ac.uk

For instructions on how to order reprints of this article, please visit our website: www.emeraldgrouppublishing.com/licensing/reprints.htm

Or contact us for further details: permissions@emeraldinsight.com 